
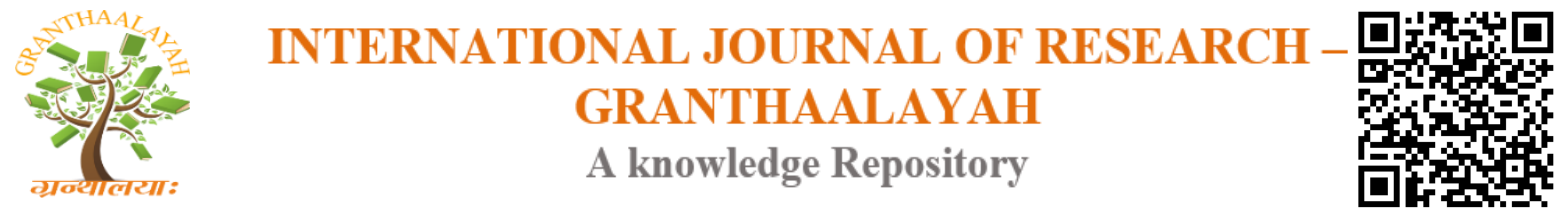

Science

\title{
CLINICAL EVALUATION OF EFFECTS OF LOW-LEVEL LASERS ON PAIN DURING CAVITY PREPARATION
}

\author{
Dr Maj Summerdeep Kaur ${ }^{* 1}$, Dr Lt Col Sonali Sharma ${ }^{2}$, Dr Maj Pankaj Awasthi ${ }^{3}$ \\ ${ }^{*} 1,3$ PG Resident, Dept of Conservative Dentistry \& Endodontics, Army Dental Centre \\ (Research \& Referral), Delhi - 110010, India \\ ${ }^{2}$ Professor, Dept of Conservative Dentistry \& Endodontics, Army Dental Centre \\ (Research \& Referral), Delhi - 110010, India
}

\begin{abstract}
Aim: To study the effects of low level laser on pain during cavity preparation.

Background: Laser irradiation stabilizes the nerve membrane through an increase in adenosine triphosphate (ATP) production and enhanced redox system of the cell. Dental pulp is innervated by non- myelinated $\mathrm{C}$ fibres. Laser irradiation reduces the conduction of Ad and $\mathrm{C}$ fibres (small diameter fibres), both of which transmit nociceptive pain. The stabilization of the nerve membrane increases neural latency and decreases pain transmission. This study explores whether preirradiation with laser reduces pain perception during cavity preparation.

Methodology: A clinical study was done on 50 patients reporting to Army Dental Centre(R\&R) having moderate and deep size carious lesions on first/second premolar's bilaterally. The patients selected was apprehensive. On one side, low level lasers irradiation was done prior cavity preparation (Test). On the other contralateral tooth type cavity preparation was done without local anesthesia (Control). The patients pain threshold was noted for both control and test groups using Visual Analogue Scale (VAS). The data was computed and statiscally analyzed.

Results: The patients exhibited reduce pain perception in tooth which had prior laser irradiation as compared to the control group.

Conclusion: Laser analgesia with low level lasers can be used as routine protocol for reducing pain perception in apprehensive patients undergoing cavity preparation.

Keywords: Laser Analgesia; Low Level Lasers; Cavity Preparation.

Cite This Article: Dr Maj Summerdeep Kaur, Dr Lt Col Sonali Sharma, and Dr Maj Pankaj Awasthi. (2018). "CLINICAL EVALUATION OF EFFECTS OF LOW-LEVEL LASERS ON PAIN DURING CAVITY PREPARATION." International Journal of Research Granthaalayah, 6(10), 81-86. https://doi.org/10.29121/granthaalayah.v6.i10.2018.1164.
\end{abstract}

\section{Introduction}

Conventional treatment protocol involving cavity preparation and restoration by high speed drilling is most often the cause of discomfort for the patient because of its association with pain 
and sensitivity. The most effective method so far for pain reduction is injectable local anesthesia for any operative procedure. Even though there are many disadvantages like allergies, systemic side effect, it is still one of the most common method used to relieve pain in dentistry [1]. The impetus for considering other suitable alternative to local anesthesia was patient who exhibit needle phobia. Even though the pain can be eliminated by use of local anesthesia but fear of needle is the major concern for the dentist [2]. Any procedure which decrease both pain and fear is in great demand. Alternatives like anesthetic cream Eutetic mixture of local anesthesia (EMLA) was also used but due to unpleasant taste its use was discontinued even though it produces good pulpal anesthesia. The use of hypnosis was also tested which had varying degree of clinical success and studies on electronic analgesia for pain relieve were also conducted but the results are not very conclusive. Biostimulation by lasers has been documented to be devoid of any pain and side effects, has thus gained popularity [3-5].

Low level Lasers are potential alternative for local anesthesia for cavity preparation. Also known as soft tissue laser, studies have been going on for than three decades. 10 to $50 \mathrm{Mw}$ is the power output required for low level lasers. They have poor absorption in water because of small wavelength used, hence penetration is into hard and soft tissue is in range 3 to $15 \mathrm{~mm}$ [6]. Studies by Parkin and Miller in 1992 reported irradiation by laser produced analgesia sufficient for cavity preparation in tooth without causing any discomfort to patients [7]. Wide Range of laser parameters has been recommended by manufacturers but no definite optimum parameters has been defined for every clinical condition.

Low level laser are used for its various advantages like its anti-inflammatory and regenerative effect in dentistry. Its role in treatment of pain associated with TMJ disorder, trigeminal neuralgia has been published. It is also used for treatment of dental hypersensitivity [8,9].

Analgesic effects on dental pulp was first noted in early 1990 with Nd: YAG laser. Animal studies on lasers confirms its effect due to conduction blockage of peripheral and central sensory nerve. In addition to disruption of sodium potassium pump and loss of conduction of impulse, release of endorphins hormone by brain was also a proposed but still its mechanism of action remains unclear [6]. Histological Examination of pulpal tissue of teeth which were treated by lasers for analgesic effect showed no adverse effect in short as well as long term basic [6].

The anesthesia produced by low power laser generates high power pulse with deep tissue penetration and minimum heat generation has led to interest for its use in pulpal anesthesia in operative procedure which neither causes numbness nor anxiety associated with injection [10-14]. Strong evidence shown in clinical trials and studies conducted on animals suggest neural basis that results in conduction blockage by which laser achieve pulpal anesthesia. The aim of the study was to evaluate the analgesic effect of low level laser on cavity preparation.

\section{Material and Method}

All the guidelines for the study was established. 50 Patients of age group 15 to 30 yrs reporting to Army Dental Centre R\&R having moderate to deep size caries lesions on first / second premolar's bilaterally were selected at randomly. Informed consent was taken after explaining in detail the 
procedure of the lasers, the side effect and precaution patient might have to take. Study was approved for ethical clearance by the ethical committee of the institution.

After clinical and radiological evaluation selected patients were randomly assigned to control and test group. Parameters such as depth and locations of the caries were balanced and standardized before commencement of the study. Gallium: Aluminum: Arsenide (GaAlAs) laser of wavelength $810 \mathrm{~nm}$ with $0.5 \mathrm{~W}$ for 2 cycles of $30 \mathrm{sec}$ each was used in non contact mode was used.

Test group were treated by low level laser irradiation before cavity preparation with high speed drilling. On the contralateral tooth type (control) preparation was completed without laser irradiation or local anesthesia.

To achieve anesthesia with low level laser, irradiation was done in non contact mode on the region of mental nerve and gingival margin bucally and lingually, $2 \mathrm{~mm}$ away from tooth surface and was moved on it for 2 cycles of $30 \mathrm{sec}$ each. After irradiation, cavity preparation was completed and restored with composite. Patient were asked to rate their pain perception on visual analog scale (VAS) from 0 to 10 for both test and control group. The data was computed and statically analyzed.
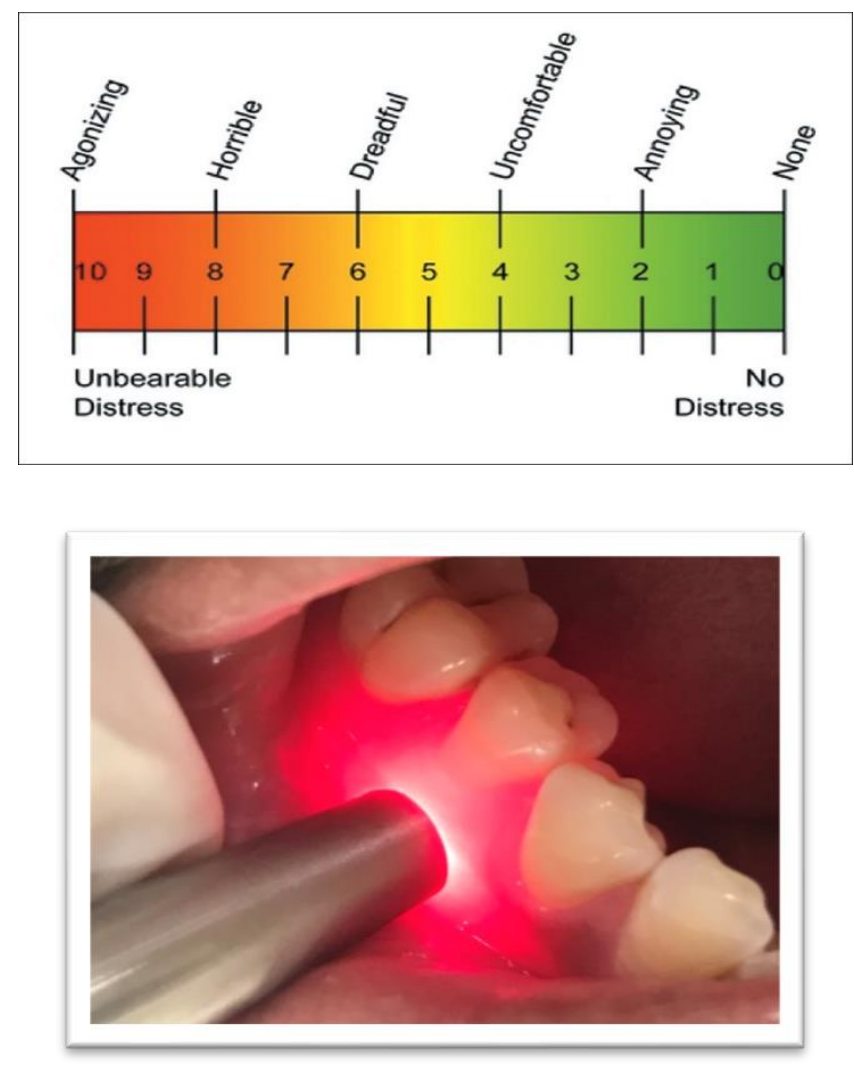

\section{Results}

The results of Student $t$ test revealed statistically significant difference between test and control ( $p$ $<0.001)$. Visual analog scale (VAS) score was higher for control than test. Pain assessment of test and control groups: 


\begin{tabular}{|l|l|l|c|l|}
\hline Group & Mean & Standard deviation & t - value & p - value \\
\hline Test & 1.64 & 1.07548 & 6.724 & $<0.001$ \\
\hline Control & 5.56 & 2.70924 & & \\
\hline
\end{tabular}

VAS Scores:

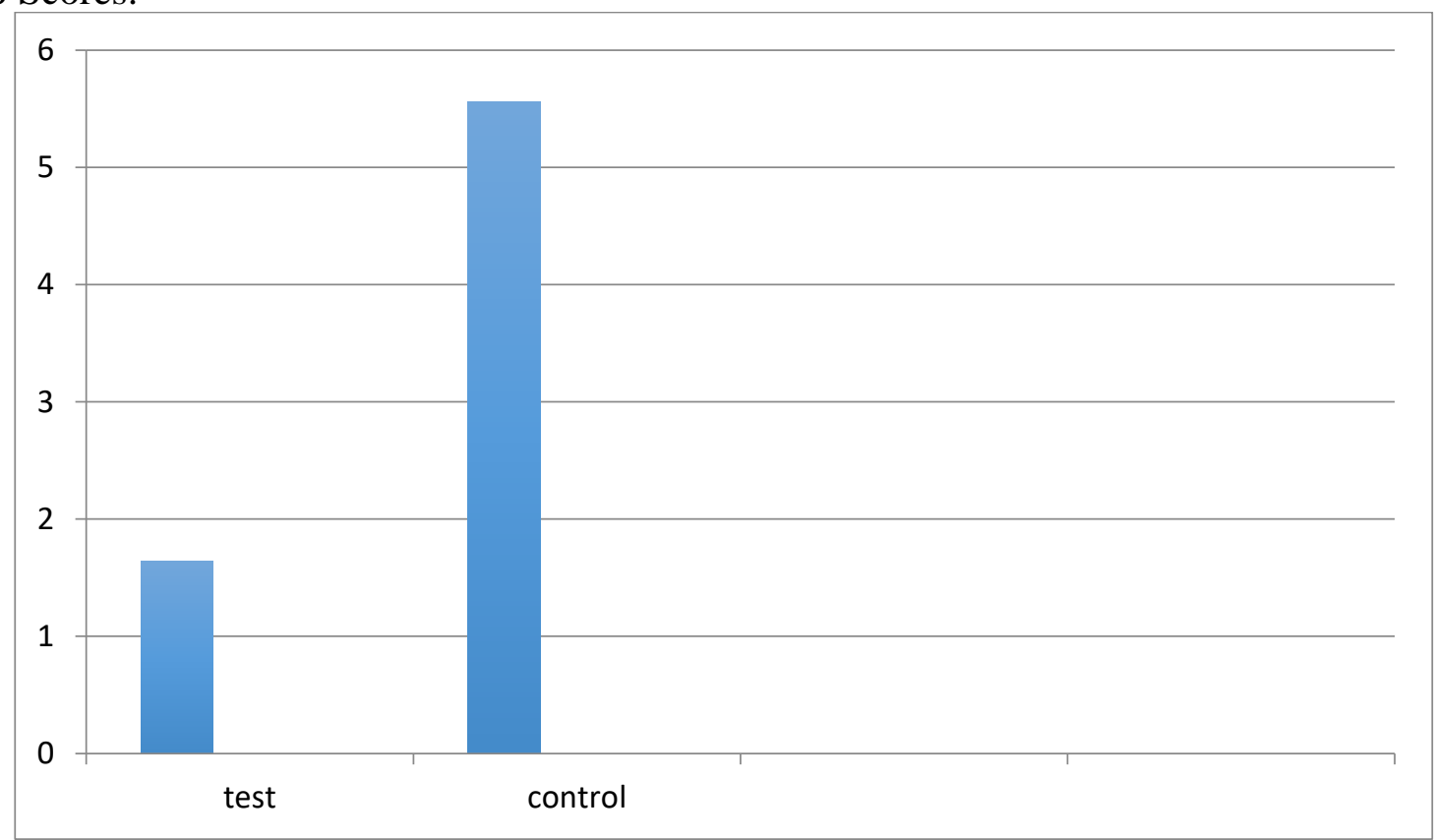

Visual analog scale (VAS) score was higher for control than test.

\section{Discussion}

Low level lasers induces very effective Pulpal analgesia in mandibular premolars by suppressing intradental nerve response to mechanical and thermal stimulus.

Orchardson et al in 1998, inserted functional spinal nerve of rat in root canal of extracted human tooth confirmed by recording action potential followed by laser irradiation. He showed that doses greater than $1.5 \mathrm{~W}$ for 1 min produced reversible anesthesia [15].

Later on in 2000 Orchardson and Whitters reported irradiation with laser, at $0.6-1.5 \mathrm{~W}$ suppress intradental nerve reversibly in response to mechanical and thermal stimulus. These results are consistent with our study however in our study we have used low level lasers and got desired results unlike in mentioned studies where results were obtained with high wattage [16].

This study clearly confirmed that low level laser irradiation by diode laser of wavelength $810 \mathrm{~nm}$ with $0.5 \mathrm{~W}$ in 2 cycles of $30 \mathrm{sec}$ each in non contact mode, $2 \mathrm{~mm}$ away from the tooth surface provide minimum patient discomfort. Cavity preparation with low level laser has no side effect and it seems to be good option with fearful patients. Pain assessment by patients using VAS Scale showed median for test group was 1.64 and that for control was 6.56. This difference was statically significant $(\mathrm{p}<0.001)$. Such a procedure provides painless, non invasive alternative to local anesthesia for restorative dentistry particularly in children, those have needle phobia. Another important finding of this study was time taken for the complete procedure for the test group was 
nearly half as compared with control group. Clearly suggesting the role of pulpal analgesia that makes the complete procedure comfortable for the patient.

The disadvantage of using of laser technology over local anesthesia would be high cost and elaborate armamentarium [17]. Laser used for this study is portable. Besides induction of pulpal anesthesia, low level laser is useful and is very beneficial in many ways like soft tissue ablation, endodontic disinfection, bleaching, increases fluoride uptake, hemostasis, treating dentinal hypersensitivity and biomodulation $[17,18]$.

Most commonly available low level laser use semiconductor diode laser. Generally theses are variations of Gallium: Aluminium: Arsenide (GaAlAs) which emit wavelength of 700-940 nm in the near infrared spectrum or Indium: Gallium: Arsenide: Phosphorous (In GaAsP) having wavelength of $600-680 \mathrm{~nm}$ in the red portion of the visible spectrum range $[19,20]$.

In numerous clinical studies laser parameters used were variable and incomplete [21]. Institute for laser dentistry (Clinical procedures performed with the American Dental Laser, August, 1991) recommended a set of laser parameters for induction of pulpal analgesia for Nd: YAG laser (1-1.5 $\mathrm{W}$ average power for 3-4 min; total energy $180-360 \mathrm{~J}$, at $10-15 \mathrm{~Hz}$ with a aspirator cooling). Following this clinical study, Whitters in 1995 carried out a clinical study to testiseptithis claim by irradiating the crown of a maxillary central incisor with a laser atisepia high average power of 1.70 $\mathrm{W}$, for $3 \mathrm{~min}$, total energy of $305 \mathrm{~J}, 15 \mathrm{~Hz}$ without aspirator cooling. They reported $80 \%$ power to detect a mean difference of 4 EPT units but did nots is ishow that such increases in EPT units adequately indicate pulpal analgesiais

In contract, in our study the low level lasers intensity was less than above mentioned study with no adverse effects on pulp [15]. No patient reported any discomfort, numbness or pain during laser irradiation similar to Arndt-Schulz's principle according to which for any given intensity below or above the threshold limit there will be insignificant cellular or biochemical response [22,23].

\section{Conclusion}

Low level laser application prior to cavity preparation makes the procedure comfortable shorter and very effective. It allays fear, reduces dental phobia and stress associated with dental procedure both for the patients and dental operator. Further studies should be conducted to include optimal dose and duration of application of low level laser. Such clinical study is important in formulating a definite dental / pulpal analgesia protocol.

\section{References}

[1] Armfield J (2010). The extent and nature of dental fear and phobia in Australia. Aust Dent J 55:368377.

[2] Bedi R, Sutcliffe P, Donnan PT, McConnachie J (1992). The prevalence of dental anxiety in a group of 13- and 14-year-old Scottish children. Int J Paediatr Dent 2:17-24.

[3] Zhou YC (1984). An advanced clinical trial with laser acupuncture anaesthesia for minor operations in the oro-maxillofacial region. Laser Surg Med 4:297-303. 
[4] Markovic AB, Todorovic L (2006). Postoperative analgesia after lower third molar surgery: contribution of the use of long-acting local anaesthetics, low-power laser and diclofenac. Oral Surg Oral Med Oral Pathol Oral Radiol Endod 102:e4-e8.

[5] Tanboga I, Eren F, Altinok B, Peker S, ErtugralisepiF (2011). The effect of low level laser therapy on pain during dental tooth-cavity preparation in children. Eur Arch Paediatr Dent 12:93-95.

[6] Mortiz et al(2006) oral laser application - quintessence publishing Co. Inc. Berlin, Germany.

[7] ParkinsF,Miller R.Nd:YAG laser analgesia of dentin. J Dent Res 1992;71: 162(abstr 450).

[8] Pinheiro AL, Manzi CT, Vieira AL, Rolim AB. Low-level laser therapy is an important tool to treat disorders of the maxillofacial region. J Clin Laser Med Surg.1998 Aug;16(4):223-6.

[9] Walsh LJ. The current status of low level laser therapy in dentistry. Part 2. Hard tissue application. Aust Dent J.1997;42(5):302-6

[10] Whitters CJ, Hall A, Creanor SL, Moseley H, Gilmour WH, Strang R (1995): A clinical study of pulsed Nd: YAG laser-induced pulpal analgesia. J Dent. 23(3):145-50.

[11] Chan A, Armati P, Moorthy AP (2012): Pulsed Nd:YAG Laser Induces Pulpal Analgesia: A Randomized Clinical Trial. J Dent Res. 91(7):S79- S84.

[12] Myers T, McDaniel J (1991): Review of clinical applications. J CA Dent Assoc. 19:25-30.

[13] Nagasawa A (1984): The anaesthetic effect of Nd:YAG laser in dental treatment. Jpn J Med Bio Eng. 22:830-1. Matsumoto K (1994): Tooth pain control by laser. Loh HS, editor. Bologna, Italy: Monduzzi Editore.

[14] Orchardson R, Peacock J, Whitters CJ (1998). Effects of pulsed Nd:YAG laser radiation on action potential conduction in nerve fibers inside teeth in vitro. J Dent 26:421-426.

[15] Orchardson R, Whitters CJ (2000). Effect of HeNe and pulsed Nd:YAG laser irradiation on intradental nerve responses to mechanical stimulation of dentine. Lasers Surg Med 26:241-249.

[16] Funato A, Nakamura Y, Matsumoto K (1991). Effects of Nd:YAG laser irradiation on microcirculation. J Clin Laser Med Surg 9:467-474.

[17] Myers T, McDaniel J (1991). Review of clinical applications. J CA Dent Assoc 19:25-30.

[18] Martens LC. Laser physics and a review of laser applications in dentistry for children. Eur Arch Paediatr Dent 2011; 12:61-67.

[19] Walsh LJ. The current status of low level laser therapy in dentistry. Part 2. Hard tissue application. Aust Dent J.1997;42(5):302-6.

[20] C how R, Armati P, Laakso EL, Bjordal JM, Baxter GD (2011). Inhibitory effects of laser irradiation on peripheral mammalian nerves and relevance to analgesic effects: A systematic review. Photomed Laser Surg 29:365-381.

[21] Arndt-Schulz G. Munch (1923): MedWschr. 70:1005-6.

[22] Chung H, Dai T, Sharma SK, Huang YY, Carroll JD, Hamblin MR (2012): The nuts and bolts of low- level laser (light) therapy. Annals Biomedical Eng. 40(2):516-33.

\footnotetext{
*Corresponding author.

E-mail address: summersangha@ gmail.com
} 